\title{
Preparation, Characterization, and Activity Evaluation of $\mathrm{CuO} / \mathrm{F}^{-\mathrm{TiO}_{2}}$ Photocatalyst
}

\author{
Zhang Jinfeng, ${ }^{1}$ Yang Yunguang, ${ }^{2}$ and Liu Wei ${ }^{2}$ \\ ${ }^{1}$ Department of Physics, Huaibei Normal University, Anhui, Huaibei 235000, China \\ ${ }^{2}$ Department of Chemistry, Huaibei Normal University, Anhui, Huaibei 235000, China \\ Correspondence should be addressed to Liu Wei, weiliu@chnu.edu.cn
}

Received 21 November 2011; Accepted 31 December 2011

Academic Editor: Baibiao Huang

Copyright ( 2012 Zhang Jinfeng et al. This is an open access article distributed under the Creative Commons Attribution License, which permits unrestricted use, distribution, and reproduction in any medium, provided the original work is properly cited.

$\mathrm{CuO} / \mathrm{F}-\mathrm{TiO}_{2}$ nanoparticle photocatalyst was prepared by ball milling. The photocatalyst was characterized by X-ray powder diffraction, scanning electron microscopy, transmission electron microscopy, UV-Vis diffuse reflectance spectroscopy, and photoluminescence emission spectroscopy. The photocatalytic activity was evaluated by photocatalytic oxidation of rhodamine $\mathrm{B}$ and reduction of $\mathrm{Cr}_{2} \mathrm{O}_{7}{ }^{2-}$. The results showed that, for $\mathrm{F}_{-} \mathrm{TiO}_{2}$ photocatalyst, the photooxidation activity increases remarkably with the increasing amount of $\mathrm{NH}_{4} \mathrm{~F}$ up to $1.0 \mathrm{~g}$, and the photoreduction activity decreases gradually with the increase in the amounts of $\mathrm{NH}_{4} \mathrm{~F}$. For the $\mathrm{CuO} / \mathrm{F}-\mathrm{TiO}_{2}$ photocatalyst, the photoreduction activity increases greatly with the increase in the amount of doped p-CuO up to $1.0 \mathrm{wt} . \%$, and the photooxidation activity decreases rapidly with the increase in the amounts of doped p-CuO. Compared with pure $\mathrm{TiO}_{2}$, the photoabsorption wavelength range of the $\mathrm{CuO} / \mathrm{F}-\mathrm{TiO}_{2}$ and $\mathrm{F}-\mathrm{TiO}_{2}$ photocatalysts red shifts and improves the utilization of the total spectrum. The effect of ball milling time on the photocatalytic activity of the photocatalysts was also investigated. The mechanisms of influence on the photocatalytic activity of the photocatalysts were also discussed.

\section{Introduction}

Since Fujishima and Honda discovered the photocatalytic splitting of water on titanium dioxide $\left(\mathrm{TiO}_{2}\right)$ electrodes in 1972 [1], $\mathrm{TiO}_{2}$ as a photocatalyst has been extensively studied because it has relatively high photocatalytic activity, biological and chemical stability, low cost, nontoxicity, and longterm stability against photocorrosion and chemical corrosion [2-9]. However, the photocatalytic activity of $\mathrm{TiO}_{2}$ is limited to irradiation wavelengths in the UV region, thus the effective utilization of solar energy is limited to about 3-5\% of the total solar spectrum. Some problems still remain to be solved in its application, such as the fast recombination of photogenerated electron-hole pairs. Therefore, improving photocatalytic activity by modification has become a hot topic among the researchers in the near decade $[10,11]$. Many investigators have quested for various methods, such as doping transition metals [12-15], doping nonmetallic elements [1620], and forming composite photocatalysts from different semiconductors [21-24], and so forth, to enhance the photocatalytic activity of $\mathrm{TiO}_{2}$ and to improve the utilization of visible light.
Recently, fluorinated $\mathrm{TiO}_{2}\left(\mathrm{~F}-\mathrm{TiO}_{2}\right)$ had been investigated extensively. The results showed that the photocatalytic oxidation activity of the $\mathrm{F}_{-} \mathrm{TiO}_{2}$ is much higher than that of $\mathrm{TiO}_{2}$ by reason of the extension of the photoabsorption wavelength as a result of doped F element [25-27]. The $p-n$ junction photocatalysts $\mathrm{NiO} / \mathrm{TiO}_{2}$ and $\mathrm{p}-\mathrm{ZnO} / \mathrm{n}-\mathrm{TiO}_{2}$ have been studied in our laboratory $[21,28]$. The results showed that, compared with pure $\mathrm{TiO}_{2}$, the $\mathrm{p}-\mathrm{n}$ junction photocatalysts have higher photocatalytic reduction activity, but lower photocatalytic oxidation activity. It is known that $\mathrm{CuO}$ is a ptype semiconductor [29]. When p-type $\mathrm{CuO}$ and fluorinated n-type $\mathrm{TiO}_{2}$ integrates, a $\mathrm{p}$-n heterojunction photocatalyst $\mathrm{CuO} / \mathrm{F}-\mathrm{TiO}_{2}$ will be formed, which may improve charge separation and photocatalytic activity of the photocatalyst.

In this paper, $\mathrm{CuO} / \mathrm{F}-\mathrm{TiO}_{2}$ powder was prepared by ball milling using $\mathrm{NH}_{4} \mathrm{~F}$ solution as a disperser. The photocatalytic activity of the photocatalyst was evaluated by photocatalytic oxidation of rhodamine $\mathrm{B}(\mathrm{RhB})$ and reduction of $\mathrm{Cr}_{2} \mathrm{O}_{7}{ }^{2-}$. The desired result was obtained. The effect of ball milling time on the photocatalytic activity of the photocatalysts was also investigated. The mechanisms of 
influence on the photocatalytic activity of the $\mathrm{CuO} / \mathrm{F}$ $\mathrm{TiO}_{2}$ photocatalyst were also discussed.

\section{Experimental}

2.1. Materials. $\mathrm{The}^{\mathrm{TiO}} 2$ powder (Anatase $90 \%$, Rutile $10 \%$, with crystallite size of about 50-60 nm) used in the experiments was supplied by Sinopharm Chemical Reagent Co, Ltd. $\mathrm{Cu}\left(\mathrm{NO}_{3}\right)_{2} \cdot 3 \mathrm{H}_{2} \mathrm{O}$ was supplied by Shanghai Reagent Factory (purity 99.9\%). $\mathrm{NH}_{4} \mathrm{~F}$, Rhodamine $\mathrm{B}$, and other chemicals used in the experiments were purchased from Shanghai and other China Chemical Reagent Ltd. They were of analytically pure grade. Deionized water was used throughout this study.

2.2. Preparation of $\mathrm{F}-\mathrm{TiO}_{2}$ and $\mathrm{CuO} / \mathrm{F}-\mathrm{TiO}_{2}$. Nanoparticle $\mathrm{CuO}$ was synthesized by heat treatment of $\mathrm{Cu}\left(\mathrm{NO}_{3}\right)_{2} \cdot 3 \mathrm{H}_{2} \mathrm{O}$ at $500^{\circ} \mathrm{C}$ for $6 \mathrm{~h}$ in air, and the crystallite size is about $80 \mathrm{~nm}$. The preparation of $\mathrm{F}-\mathrm{TiO}_{2}$ photocatalyst was carried out in a ND2-2L ball mill (made in Tianzun Electronics Co, Ltd., Nanjing University). The procedures for the preparation of F-TiO ${ }_{2}$ are as follows: $5.0 \mathrm{~g} \mathrm{TiO}_{2}$ powder and three different sizes of zirconia balls were mixed in the zirconia tank, and then a certain amount of $\mathrm{NH}_{4} \mathrm{~F}(0 \mathrm{~g}, 0.2 \mathrm{~g}, 0.5 \mathrm{~g}, 1.0 \mathrm{~g}$, $1.5 \mathrm{~g}, 2.0 \mathrm{~g}, 2.5 \mathrm{~g})$ and $\mathrm{H}_{2} \mathrm{O}(5 \mathrm{~mL})$ was added. After being milled for a certain time $(0-24 \mathrm{~h})$ at the speed of $550 \mathrm{rpm}$, the wet powder was dried at $110^{\circ} \mathrm{C}$ in air. The final samples were used for the determination of photocatalytic activity and characterization. $\mathrm{CuO} / \mathrm{F}-\mathrm{TiO}_{2}$ photocatalyst was prepared in the same procedure. For each sample, $1.0 \mathrm{~g}$ $\mathrm{NH}_{4} \mathrm{~F}, 5.0 \mathrm{~g} \mathrm{TiO}$, and $5.0 \mathrm{~mL} \mathrm{H}_{2} \mathrm{O}$ were added in a zirconia tank, varying the weight ratio of $\mathrm{CuO}(0 \mathrm{wt} . \%, 0.1 \mathrm{wt} \%$, 0.3 wt. $\%, 0.5$ wt. $\%, 1.0$ wt. $\%, 3.0$ wt. $\%$, and 5.0 wt. $\%$ ), and then different $\mathrm{CuO} / \mathrm{F}-\mathrm{TiO}_{2}$ powder samples were prepared, respectively. The specific surface area of the different $\mathrm{CuO} / \mathrm{F}-$ $\mathrm{TiO}_{2}$ photocatalysts has no obvious change and it is about $24.7 \mathrm{~m}^{2} / \mathrm{g}$. The flow chart of preparation of the $\mathrm{CuO} / \mathrm{F}-\mathrm{TiO}_{2}$ is given in Scheme 1.

2.3. Photoreaction Apparatus and Procedure. Experiments were carried out in a photoreaction apparatus [21,28]. The photoreaction apparatus consists of two parts. The first part is an annular quartz tube. A $375 \mathrm{~W}$ medium pressure mercury lamp (Institute of Electric Light Source, Beijing), with a maximum emission at about $365 \mathrm{~nm}$, was used as light sources. The lamp is laid in the empty chamber of the annular tube, and running water passes through an inner thimble of the annular tube. Owing to continuous cooling, the temperature of the reaction solution is maintained at approximately $30^{\circ} \mathrm{C}$. The second part is an unsealed beaker with a diameter of $12 \mathrm{~cm}$. At the start of the experiment, the reaction solution (volume, $300 \mathrm{~mL}$ ) containing reactants and photocatalyst was put in the unsealed beakers, and a magnetic stirring device was used to stir the reaction solution. The distance between the light source and the surface of the reaction solution is $11 \mathrm{~cm}$. In the experiments, the initial $\mathrm{pH}$ of the reaction solution was 5.0, the amount of the photocatalyst used was $2.0 \mathrm{~g} / \mathrm{L}$, and the initial concentrations of
$\mathrm{Cr}_{2} \mathrm{O}_{7}{ }^{2-}$ and $\mathrm{RhB}$ were $1.0 \times 10^{-4}$ and $1.0 \times 10^{-5} \mathrm{~mol} / \mathrm{L}$, respectively. In order to disperse the photocatalyst powder, the suspensions were ultrasonically vibrated for 10 or $20 \mathrm{~min}$ prior to irradiation. After illumination, the samples taken from the reaction suspension were centrifuged at $7000 \mathrm{rpm}$ for $20 \mathrm{~min}$ and filtered through a $0.2 \mu \mathrm{m}$ millipore filter to remove the particles. The filtrate was then analyzed. In order to determine the reproducibility of the results, at least duplicated runs were carried out for each condition for averaging the results, and the experimental error was found to be within $\pm 4 \%$.

2.4. Characterization. In order to determine the crystal phase composition and the crystallite size of the photocatalysts, $\mathrm{X}$-ray diffraction measurement was carried out at room temperature using a DX-2000 X-ray powder diffractometer with $\mathrm{Cu} \mathrm{K} \alpha$ radiation and a scanning speed of $3 \% \mathrm{~min}$. The accelerating voltage and emission current were $40 \mathrm{kV}$ and $30 \mathrm{~mA}$, respectively. The crystallite size was calculated by Xray line broadening analysis using the Scherrer equation.

The microcrystalline structure and surface characteristics of the photocatalysts were also investigated by using (X-650 Japan) scanning electron microscope.

Transmission electron microscopy and high-resolution transmission electron microscopy (HR-TEM) images were performed with a JEOL-2010 transmission electron microscope, using an accelerating voltage of $200 \mathrm{kV}$.

UV-Vis diffuse reflectance spectra measurements were carried out using a Hitachi UV-365 spectrophotometer equipped with an integrating sphere attachment. The analysis range was from 250 to $650 \mathrm{~nm}$, and $\mathrm{BaSO}_{4}$ was used as a reflectance standard.

Photoluminescence emission spectra were recorded on a JASCO FP-6500 type fluorescence spectrophotometer over a wavelength range of $360-500 \mathrm{~nm}$.

2.5. Analysis. The concentration of $\mathrm{Cr}_{2} \mathrm{O}_{7}{ }^{2-}$ in the solution is determined spectrophotometrically using diphenylcarbazide reagent as a developer. The concentration of rhodamine $\mathrm{B}(\mathrm{RhB})$ in the solution is determined spectrophotometrically. The photoreduction efficiency of $\mathrm{Cr}_{2} \mathrm{O}_{7}{ }^{2-}$ and the photooxidation efficiency of rhodamine $\mathrm{B}$ were calculated from the following expression:

$$
\eta=\left[\frac{\left(C_{0}-C_{t}\right)}{C_{0}}\right] \times 100 \%,
$$

where $\eta$ is the photocatalytic efficiency; $C_{0}$ is the concentration of reactant before illumination; $C_{t}$ is the concentration of reactant after illumination time $t$.

\section{Results and Discussion}

\subsection{Characterization of Photocatalysts}

3.1.1. XRD Analysis. The fixed ball milling time is $6 \mathrm{~h}$. The XRD patterns of different photocatalysts are shown in Figure 1. It is clear that, when the amount of doped $\mathrm{CuO}$ is less than $5.0 \mathrm{wt} . \%$, the diffraction peaks of $\mathrm{CuO}$ cannot be 


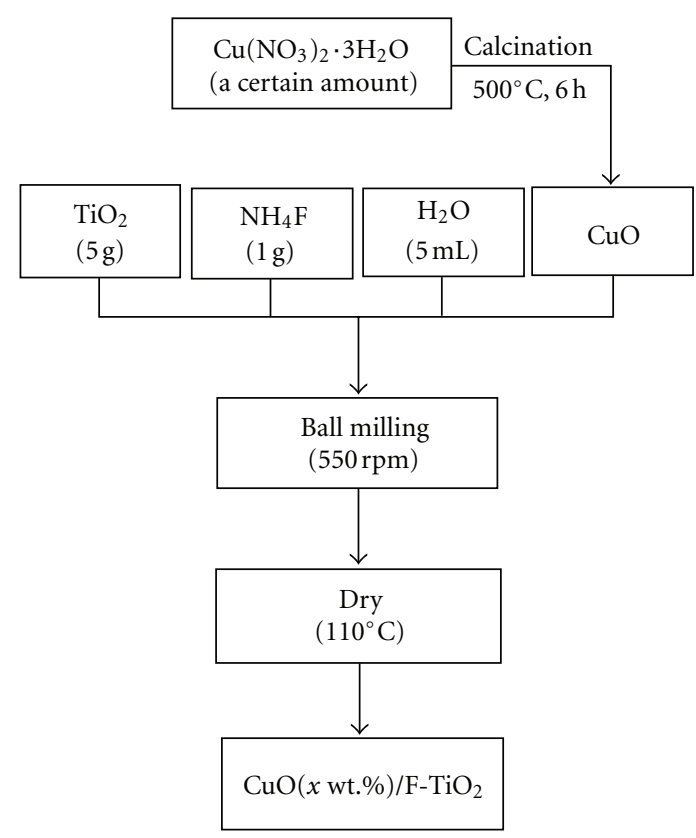

Scheme 1: The flow chart of preparation of the $\mathrm{CuO} / \mathrm{F}-\mathrm{TiO}_{2}$.

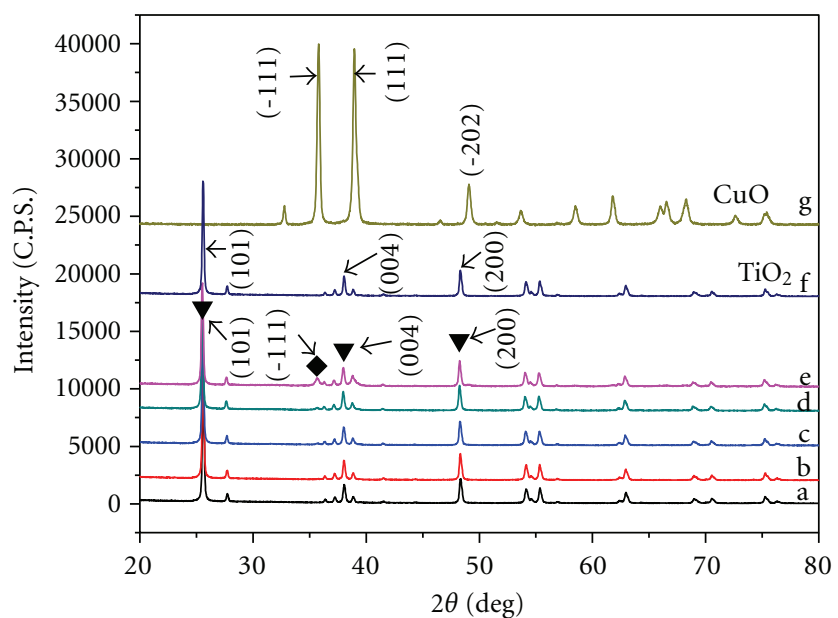

$\nabla \mathrm{TiO}_{2}$

$\bullet \mathrm{CuO}$

Figure 1: XRD patterns of different photocatalysts. (a) $\mathrm{F}_{-} \mathrm{TiO}_{2}$, (b) $\mathrm{CuO}(0.1 \mathrm{wt} . \%) / \mathrm{F}-\mathrm{TiO}_{2}$, (c) $\mathrm{CuO}(1.0 \mathrm{wt} . \%) / \mathrm{F}-\mathrm{TiO}{ }_{2},(\mathrm{~d}) \mathrm{CuO}$ (5.0 wt.\%)/F- $-\mathrm{TiO}_{2}$, (e) $\mathrm{CuO}\left(10.0\right.$ wt.\%)/F- $-\mathrm{TiO}_{2}$, (f) $\mathrm{TiO}_{2}$, and (g) $\mathrm{CuO}$.

found in XRD patterns. This illustrates that $\mathrm{CuO}$ is highly dispersed in the bulk phase of the catalyst. When the amount of doped $\mathrm{CuO}$ is higher than $5.0 \mathrm{wt} . \%$, the diffraction peaks of $\mathrm{CuO}$ can be found in XRD patterns. Since no new crystal phases are found, it can be concluded that a new solid is not formed in the ball milling process of $\mathrm{TiO}_{2}, \mathrm{NH}_{4} \mathrm{~F}$, and $\mathrm{CuO}$, or probably because the new materials content are too low to allow detection of their reflection peaks. The similar result was reported in [30]. It is known by the calculation from the Scherrer equation that the diameter of the photocatalyst is not obviously changed. The crystallite size is about $50 \mathrm{~nm}$.
3.1.2. SEM Analysis. SEM was used to investigate the morphology of the samples. Figure 2 shows SEM images of $\mathrm{CuO}$ (1.0 wt.\%)/F- $\mathrm{TiO}_{2}$ photocatalysts ball milled for 6 and $24 \mathrm{~h}$, respectively. It can be seen that the appearance is shapeless sheet, and the average diameter of the photocatalyst is about $50-60 \mathrm{~nm}$. The result is the same as that of XRD. From Figure 2, it also can be seen that, when the ball milling time is $6 \mathrm{~h}$, the dispersion degree of the sample is higher than that of the sample ball milled for $24 \mathrm{~h}$. Namely, when the ball milling time is longer than the optimum time, with the increase in the ball milling time, the fresh surfaces formed by 


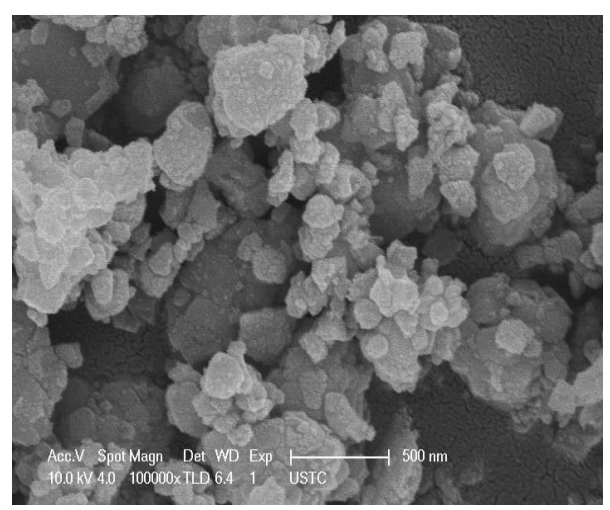

(a)

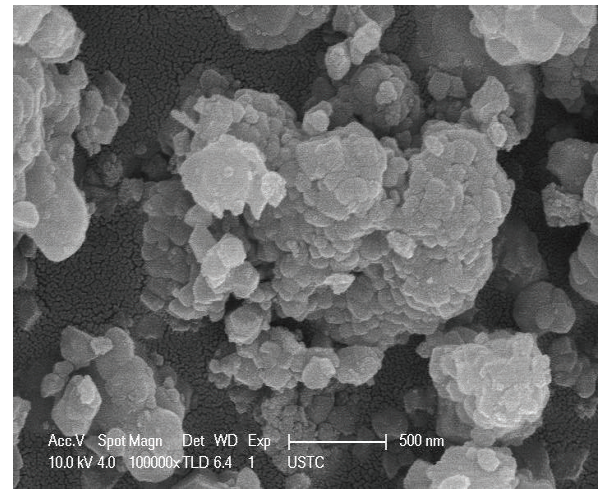

(b)

Figure 2: SEM images of $\mathrm{CuO}(1.0 \mathrm{wt} . \%) / \mathrm{F}^{-\mathrm{TiO}_{2}}$ photocatalysts. (a) $\mathrm{CuO}(1.0 \mathrm{wt} . \%) / \mathrm{F}-\mathrm{TiO}_{2}$, ball milling time $6 \mathrm{~h}$, (b) CuO (1.0 wt.\%)/F$\mathrm{TiO}_{2}$, ball milling time $24 \mathrm{~h}$.

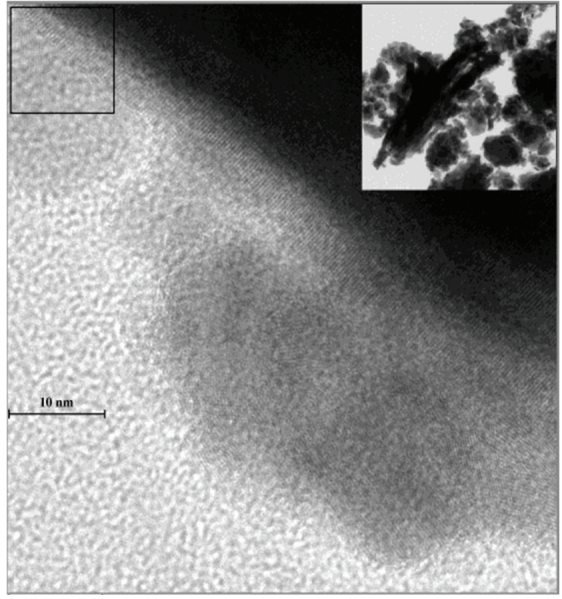

(a)

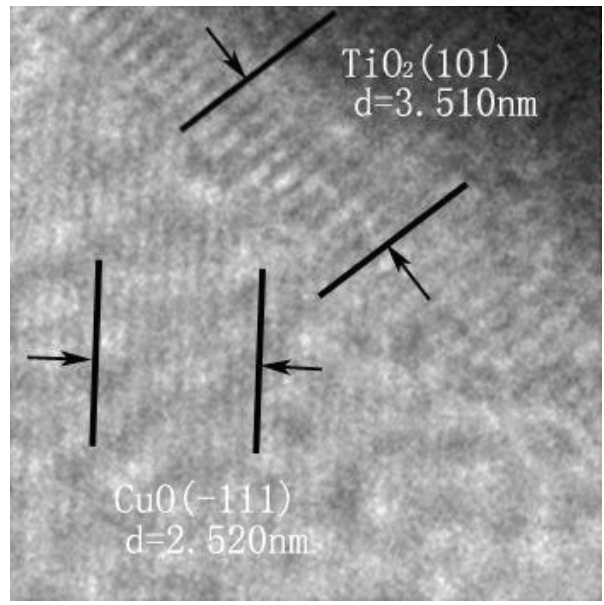

(b)

Figure 3: TEM and HR-TEM images of $\mathrm{CuO}(1.0 \mathrm{wt} . \%) / \mathrm{F}-\mathrm{TiO}_{2}$ photocatalyst: (a) TEM image, (b) HR-TEM image.

high-energy ball milling possess high surface energy and prefer to agglomerate. The similar result was reported in [30].

3.1.3. TEM Analysis. In order to investigate the interface of the sample, the $\mathrm{CuO}(1.0 \mathrm{wt} . \%) / \mathrm{F}-\mathrm{TiO}_{2}$ was chosen for TEM and high-resolution TEM characterization.

Figure 3(a) gives an overview of the typical TEM image of the $\mathrm{CuO}\left(1.0\right.$ wt. \%)/F- $\mathrm{TiO}_{2}$ photocatalyst. It clearly exhibits the existence of $\mathrm{CuO}$ nanoparticles with mean sizes of about 50-70 nm dispersing over the particle of $\mathrm{TiO}_{2}$. Figure 3(b) shows the HR-TEM image of the sample corresponding to the rectangle region of the TEM image in Figure 3(a). The upper part depicts the (101) plane of $\mathrm{TiO}_{2}$ with a spacing value of $3.510 \mathrm{~nm}$. The lower part depicts the $(-111)$ plane of $\mathrm{CuO}$ with a spacing of $2.520 \mathrm{~nm}$. The good crystalline quality and the clear interface between $\mathrm{CuO}$ and $\mathrm{TiO}_{2}$ are advantageous for the separation of the photogenerated charge carriers. Based on the above results, it is suggested that the heterojunction will be formed by ball milling between $\mathrm{CuO}$ and $\mathrm{TiO}_{2}$.

3.1.4. UV-Vis Analysis. Figure 4 shows the UV-Vis diffuse reflectance spectra of $\mathrm{F}-\mathrm{TiO}_{2}$ and a series of $\mathrm{CuO} / \mathrm{F}-\mathrm{TiO}_{2}$ photocatalysts. The samples were ball milled for $6 \mathrm{~h}$, respectively. It is known that the bandgap of $\mathrm{TiO}_{2}$ is about $3.2 \mathrm{eV}$ and it can be excited by photons with wavelengths below $387 \mathrm{~nm}$. From Figure 4, it can be seen that, compared with pure $\mathrm{TiO}_{2}$, the absorption wavelength ranges of the $\mathrm{F}-\mathrm{TiO}_{2}$ and $\mathrm{CuO} / \mathrm{F}-\mathrm{TiO}_{2}$ are extended greatly towards visible light. Compared with the $\mathrm{F}_{-}-\mathrm{TiO}_{2}$, the absorption edge of the photocatalyst $\mathrm{CuO} / \mathrm{F}-\mathrm{TiO}_{2}$ extends a little to longer wavelength, revealing the good contact between $\mathrm{CuO}$ and F$\mathrm{TiO}_{2}$ crystallites as a consequence of the interdispersion of the two phases produced by ball milling process. For $\mathrm{F}-\mathrm{TiO}_{2}$, the presence of a strong absorption band at a low wavelength in the spectra near $350 \mathrm{~nm}$ indicates that the $\mathrm{Ti}$ species are tetrahedral $\mathrm{Ti}^{4+}$. This absorption band is generally 


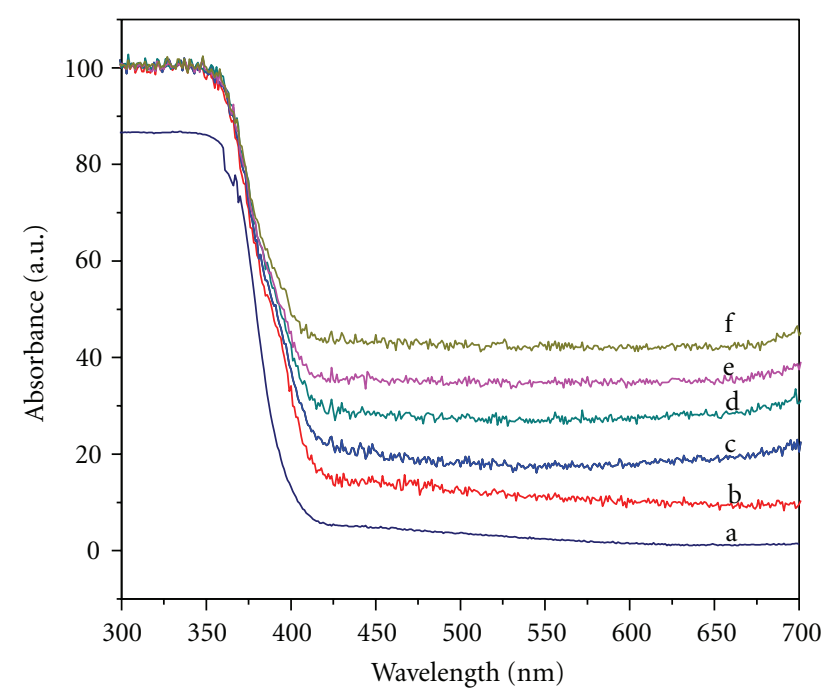

Figure 4: UV-Vis diffuse reflectance spectra of different photocatalysts. (a) $\mathrm{TiO}_{2}$, (b) $\mathrm{F}_{-} \mathrm{TiO}_{2}$, (c) $\mathrm{CuO}(0.1$ wt.\%)/F$\mathrm{TiO}_{2}$, (d) $\mathrm{CuO}(0.3$ wt.\%)/F-TiO 2 , (e) $\mathrm{CuO}(0.5$ wt.\%)/F-TiO 2 , (f) $\mathrm{CuO}(1 \mathrm{wt} . \%) / \mathrm{F}-\mathrm{TiO}_{2}$.

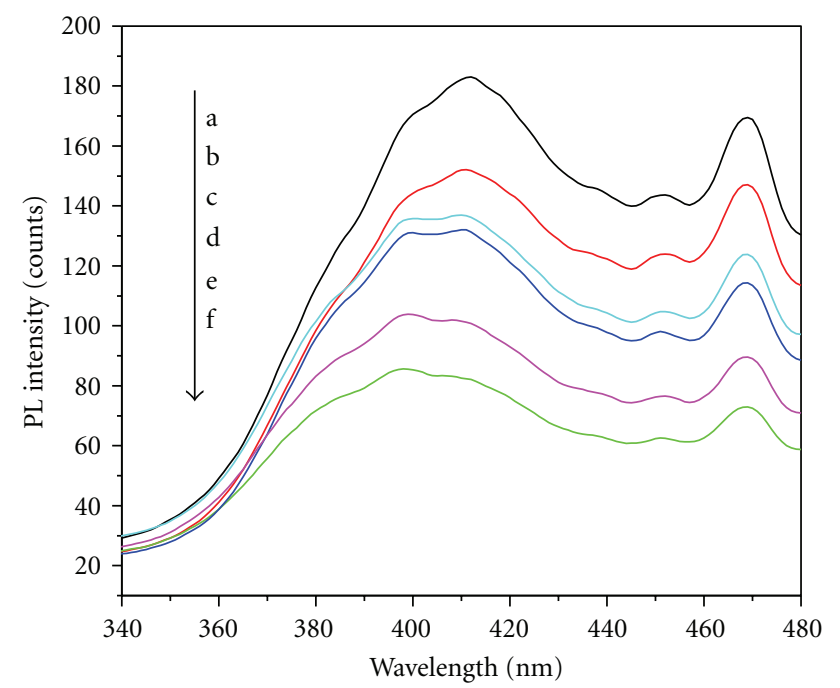

Figure 5: Photoluminescence emission spectra of photocatalysts. (a) $\mathrm{TiO}_{2}$, (b) $\mathrm{CuO}\left(0.1\right.$ wt.\%)/F- $-\mathrm{TiO}_{2}$, (c) $\mathrm{CuO}\left(0.3\right.$ wt.\%)/F- $-\mathrm{TiO}_{2}$, (d) $\mathrm{CuO}(0.5$ wt. $\%) / F-\mathrm{TiO}_{2}$, (e) $\mathrm{CuO}(3$ wt. $\%) / \mathrm{F}-\mathrm{TiO}_{2}$, (f) $\mathrm{CuO}$ (1 wt.\%)/F- $\mathrm{TiO}_{2}$.

associated with the electronic excitation of the valence band $\mathrm{O} 2 \mathrm{p}$ electron to the conduction band Ti3d level. The photoexcited wavelength range of the $\mathrm{CuO} / \mathrm{F}-\mathrm{TiO}_{2}$ photocatalyst is connected with the amount of $\mathrm{CuO}$. It increases with the increase in the amount of $\mathrm{CuO}$. In theory, because the absorption wavelength range is extended greatly towards visible light and the absorption intensity increases, the formation rate of electron-hole pairs on the photocatalyst surface also increases greatly, which results in the photocatalyst exhibiting higher photocatalytic activity. From Figure 7, it is clear that the photocatalytic activity of photocatalyst $\mathrm{CuO} / \mathrm{F}-\mathrm{TiO}_{2}$ is strongly dependent on the amount of $\mathrm{CuO}$.
In the experimental condition, the results of UV-Vis diffuse reflectance spectra are consistent with the evaluation of photoreduction activity. There were similar results in previous reports [28].

3.1.5. Photoluminescence Emission Spectra. The photoluminescence emission spectra have been widely used to investigate the efficiency of charge carrier trapping, immigration, and transfer and to understand the fate of electron-hole pairs in semiconductor particles, since photoluminescence emission is resulted from the recombination of free carriers $[31,32]$. In this study, using an ultraviolet light with a $260 \mathrm{~nm}$ wavelength as the excitation source, the fluorescence emission spectra of the different samples are shown in Figure 5. It can be seen that the samples have a stronger emission peak at around $410 \mathrm{~nm}$ and a weaker emission peak at around $470 \mathrm{~nm}[21,33]$.

From Figure 5, it is clear that the relative intensity of the emission spectra of $\mathrm{TiO}_{2}$ has the greatest relative intensity, which means that electrons and holes of $\mathrm{TiO}_{2}$ are easy to recombine. The relative intensity of the photocatalyst $\mathrm{CuO} /$ F- $-\mathrm{TiO}_{2}$ is lower than that of $\mathrm{TiO}_{2}$, showing that doping $\mathrm{CuO}$ is helpful to inhibit the recombination of electrons and holes and to improve the photocatalytic activity. The amount of $\mathrm{CuO}$ can influence the thickness of the superficial spacecharge layer of $\mathrm{TiO}_{2}$. When the amount of $\mathrm{CuO}$ is $1.0 \mathrm{wt} \%$, the relative intensity of emission spectra is the lowest, which shows that a $1.0 \mathrm{wt} . \%$ doping quantity of $\mathrm{CuO}$ can effectively restrain the recombination of photoexcited electrons and holes. When the $\mathrm{CuO}$ content is too small, due to the absence of adequate traps, the recombination rate of electron-hole pairs is higher. When the doping quantity is considerably high, the absorption of light and the generation of electronsholes are both decreased.

\subsection{Evaluation of the Photocatalytic Activity}

3.2.1. Effect of the Amount of $\mathrm{NH}_{4} \mathrm{~F}$ on the Photocatalytic Activity of $\mathrm{F}-\mathrm{TiO}_{2}$. The photocatalytic activity was investigated by photocatalytic oxidation of RhB and photocatalytic reduction of $\mathrm{Cr}_{2} \mathrm{O}_{7}{ }^{2-}$. The dark absorption and blank tests are carried out simultaneously. The dark absorption test demonstrated that the adsorption on the catalysts varied depending on the samples, while the blank experiment showed that the substrate with no photocatalyst was hardly degraded after exposure to radiation for $1 \mathrm{~h}$, illustrating that photoinduced self-sensitized photodegradation has little influence on the results of the experiment. All of the data obtained are corrected for absorption after stirring for $30 \mathrm{~min}$ in the dark. The detailed procedure was described in [34]. The fixed ball milling time is $3 \mathrm{~h}$, and fixed illumination times for the photocatalytic reduction of $\mathrm{Cr}_{2} \mathrm{O}_{7}{ }^{2-}$ and photocatalytic oxidation of RhB were $20 \mathrm{~min}$ and $10 \mathrm{~min}$, respectively. Figure 6 shows the effect of the amount of $\mathrm{NH}_{4} \mathrm{~F}$ on the photocatalytic reduction of $\mathrm{Cr}_{2} \mathrm{O}_{7}{ }^{2-}$ and photocatalytic oxidation of $\mathrm{RhB}$.

From Figure 6, it can be seen that, without $\mathrm{NH}_{4} \mathrm{~F}$ present, namely, the pure $\mathrm{TiO}_{2}$ powder photocatalyst, its photooxidation activity is the lowest, and the photooxidation efficiency for $\mathrm{RhB}$ is $15.3 \%$. The photooxidation activity of 


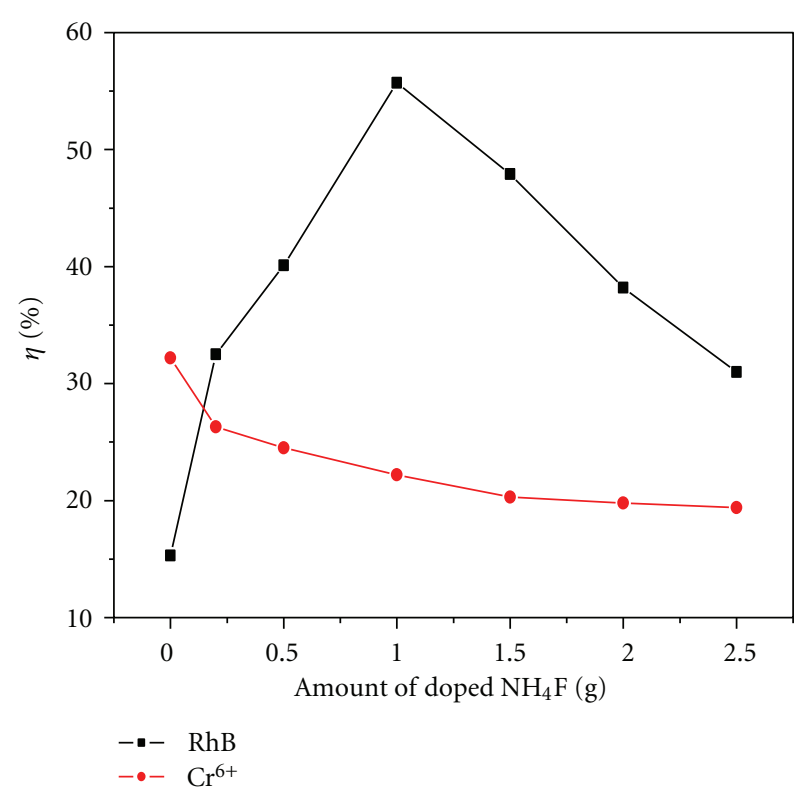

FIgURE 6: Effect of the amount of $\mathrm{NH}_{4} \mathrm{~F}$ on the photocatalytic reduction of $\mathrm{Cr}_{2} \mathrm{O}_{7}{ }^{2-}$ and photocatalytic oxidation of $\mathrm{RhB}$.

F- $-\mathrm{TiO}_{2}$ increases remarkably with the increasing amount of $\mathrm{NH}_{4} \mathrm{~F}$ up to $1.0 \mathrm{~g}$. When the amount of $\mathrm{NH}_{4} \mathrm{~F}$ is $1.0 \mathrm{~g}$, the photocatalytic activity of the $\mathrm{F}-\mathrm{TiO}_{2}$ photocatalyst is at its peak, and the photooxidation efficiency for $\mathrm{RhB}$ is $55.7 \%$. When the amount of doped $\mathrm{NH}_{4} \mathrm{~F}$ is higher than optimal amount, the photooxidation activity of $\mathrm{F}-\mathrm{TiO}_{2}$ decreases gradually. At the same time, it is clear that the photooxidation activity of $\mathrm{F}-\mathrm{TiO}_{2}$ is higher than that of pure $\mathrm{TiO}_{2}$ photocatalyst in the experimental condition. $\mathrm{F}_{-} \mathrm{TiO}_{2}$ enhanced the photodegradation of $\mathrm{RhB}$ in aqueous solutions. It was proposed that the fluorinated surface favored the generation of free $\mathrm{OH}$ radicals, which was responsible for the enhanced photocatalytic oxidation activity. The result has been reported in earlier literature [27].

However, under the same condition, for the photocatalytic reduction of $\mathrm{Cr}_{2} \mathrm{O}_{7}{ }^{2-}$, the photocatalytic reduction activity of $\mathrm{F}_{-} \mathrm{TiO}_{2}$ decreases gradually with the increase in the amounts of doped $\mathrm{NH}_{4} \mathrm{~F}$. For the pure $\mathrm{TiO}_{2}$ powder photocatalyst, its photocatalytic reduction activity is at its peak, and the photocatalytic reduction efficiency is $32.2 \%$. When the amounts of $\mathrm{NH}_{4} \mathrm{~F}$ are 0.2 and $2.0 \mathrm{~g}$, the photoreduction efficiencies are 26.3 and $19.8 \%$, respectively.

3.2.2. Effect of Amount of Doped $\mathrm{CuO}$ on the Photocatalytic Activity. In order to obtain the optimum concentration of $\mathrm{CuO}$, the effect of the amount of $\mathrm{CuO}$ on the photocatalytic activity of $\mathrm{CuO} / \mathrm{F}-\mathrm{TiO}_{2}$ photocatalyst was studied. The experiments were carried out with different concentrations of $\mathrm{CuO}$ varying from $0 \%$ to $5 \mathrm{wt} . \%$. Figure 7 shows the effects of the amount of doped $\mathrm{CuO}$ on the photocatalytic reduction of $\mathrm{Cr}_{2} \mathrm{O}_{7}{ }^{2-}$ and photocatalytic oxidation of $\mathrm{RhB}$. The fixed ball milling time for each sample was $3 \mathrm{~h}$, and the fixed illumination times for the photocatalytic reduction of $\mathrm{Cr}_{2} \mathrm{O}_{7}{ }^{2-}$ and photocatalytic oxidation of $\mathrm{RhB}$ were $20 \mathrm{~min}$

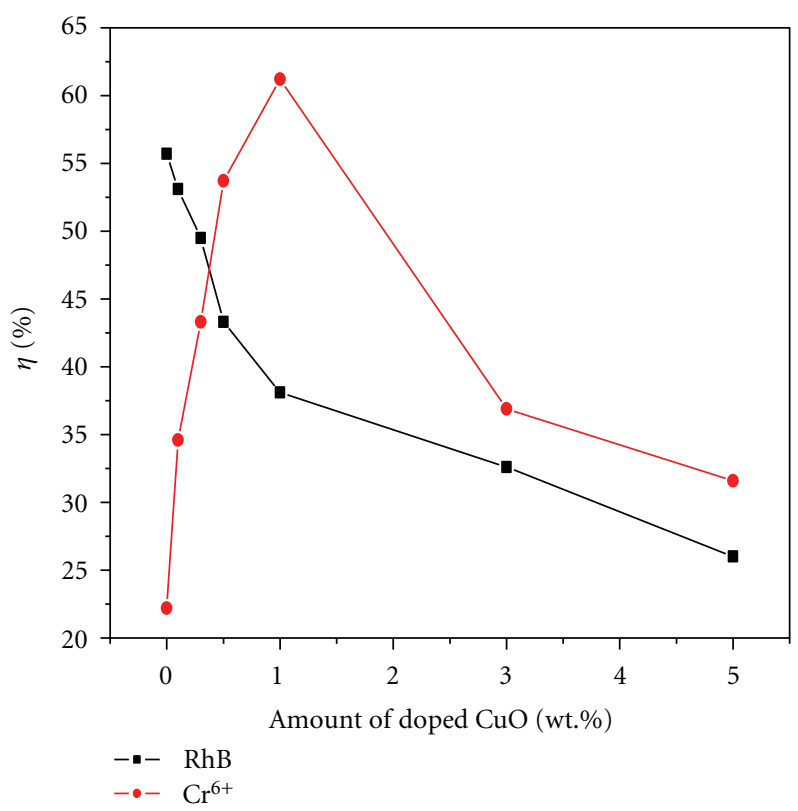

Figure 7: Effect of the amount of doped $\mathrm{CuO}$ on the photocatalytic reduction of $\mathrm{Cr}_{2} \mathrm{O}_{7}{ }^{2-}$ and photocatalytic oxidation of $\mathrm{RhB}$.

and $10 \mathrm{~min}$, respectively. The amounts of $\mathrm{TiO}_{2}$ and $\mathrm{NH}_{4} \mathrm{~F}$ were $5.0 \mathrm{~g}$ and $1.0 \mathrm{~g}$, respectively. It can be seen that, for the photocatalytic reduction of $\mathrm{Cr}_{2} \mathrm{O}_{7}{ }^{2-}$, the photoreduction activity of $\mathrm{CuO} / \mathrm{F}-\mathrm{TiO}_{2}$ increases remarkably with the increase in the amount of doped $\mathrm{CuO}$ up to $1.0 \mathrm{wt} . \%$. The optimum amount of doped $\mathrm{CuO}$ is $1.0 \mathrm{wt} . \%$. When the amount of doped is higher than the optimal amount, the photoreduction activity of the $\mathrm{CuO} / \mathrm{F}-\mathrm{TiO}_{2}$ photocatalyst decreases gradually as the amount of doped $\mathrm{p}-\mathrm{CuO}$ increases. The results also show that, without $\mathrm{CuO}$ present, namely, the $\mathrm{F}-\mathrm{TiO}_{2}$ powder photocatalyst, its photoreduction activity is the lowest, and the photoreduction efficiency is $22.2 \%$. When the amount of doped $\mathrm{p}-\mathrm{CuO}$ is $1.0 \mathrm{wt} . \%$, the photoreduction activity of $\mathrm{CuO} / \mathrm{F}-\mathrm{TiO}_{2}$ is at its peak, and the photoreduction efficiency is $61.2 \%$. From Figures 6 and 7, it is clear that the photoreduction activity of $\mathrm{CuO} / \mathrm{F}-\mathrm{TiO}_{2}$ is higher than that of pure $\mathrm{TiO}_{2}$ and $\mathrm{F}-\mathrm{TiO}_{2}$ photocatalyst. It is proposed that, when the amount of $\mathrm{CuO}$ is lower than the optimum amount, the increase of the amount of $\mathrm{CuO}$ can increase trapping sites of the carriers, which prolongs the lifetime of the carriers, thereby improving the photocatalytic activity. The other important reason is that $\mathrm{CuO}$ is a p-type semiconductor. When the $\mathrm{F}^{-\mathrm{TiO}_{2}}$ doped with suitable amount of p$\mathrm{CuO}$, both $\mathrm{p}-\mathrm{CuO}$ and $\mathrm{F}_{-}-\mathrm{TiO}_{2}$ can form the p-n junction photocatalyst by ball milling. Therefore, the photoreduction activity increases [33]. But when the amount of $\mathrm{p}-\mathrm{CuO}$ is higher than the optimum amount of doping, the high concentration dopant ions act as recombination centers of electrons and holes, decrease the thickness of the spacecharge layer on the surface of $\mathrm{TiO}_{2}$ particle, and reduce the photon absorption [21]. However, under the same condition, for the photocatalytic oxidation of $\mathrm{RhB}$, the photooxidation activity of $\mathrm{p}-\mathrm{CuO} / \mathrm{F}-\mathrm{TiO}_{2}$ decreases rapidly with the increase 


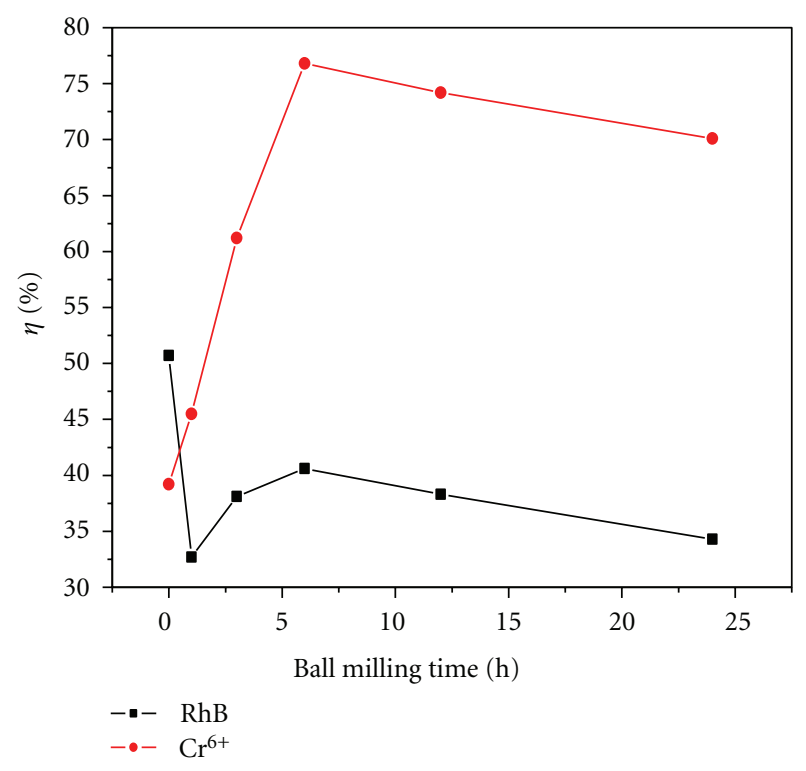

FIGURE 8: Effect of ball milling time on the photocatalytic activity.

in the amounts of doped $\mathrm{p}-\mathrm{CuO}$. For the pure $\mathrm{F}-\mathrm{TiO}_{2}$ photocatalyst, its photooxidation activity is at its peak, and the photooxidation efficiency of $\mathrm{F}-\mathrm{TiO}_{2}$ is $55.7 \%$. When the amounts of doped p-CuO are 0.3 and $1.0 \mathrm{wt} . \%$, the photooxidation efficiencies are 49.5 and $38.1 \%$, respectively.

The photocatalyst $\mathrm{CuO} / \mathrm{F}-\mathrm{TiO}_{2}$ has higher photocatalytic reduction activity than that of $\mathrm{TiO}_{2}$ and $\mathrm{F}-\mathrm{TiO}_{2}$. The possible reasons are as follows.

First, it can be explained by the $\mathrm{p}-\mathrm{n}$ junction principle $[21,28]$. It is known that $\mathrm{CuO}$ is p-type semiconductor, and $\mathrm{TiO}_{2}$ is n-type semiconductor. When p-type $\mathrm{CuO}$ and n-type $\mathrm{TiO}_{2}$ integrate $\mathrm{p}-\mathrm{n}$ junctions will be formed between $\mathrm{CuO}$ and $\mathrm{TiO}_{2}$, and the inner electric field will be also formed at the same time in the interface. So a number of micro $\mathrm{p}-\mathrm{n}$ heterojunction $\mathrm{CuO} / \mathrm{F}-\mathrm{TiO}_{2}$ photocatalysts will be formed after doping $\mathrm{CuO}$ powder into $\mathrm{TiO}_{2}$ granule. At the equilibrium, the inner electric field formed made p-type semiconductor $\mathrm{CuO}$ region have the negative charge while $\mathrm{TiO}_{2}$ region have the positive charge. The electron-hole pairs will be created under UV light illumination. With the effect of the inner electric field, the holes flow into the negative field and the electrons move to the positive field. Therefore, the photogenerated electron-hole pairs will be separated effectively by the $\mathrm{p}-\mathrm{n}$ heterojunction formed in $\mathrm{CuO} / \mathrm{F}-\mathrm{TiO}_{2}$.

Second, compared with $\mathrm{F}_{-}-\mathrm{TiO}_{2}$, the photoabsorption wavelength range of the $\mathrm{CuO} / \mathrm{F}-\mathrm{TiO}_{2}$ photocatalyst red shifts and extends the wavelength range of photoexcitation and enhances the utilization of the total spectrum. The results also show that the photoluminescence emission intensity of the $\mathrm{CuO} / \mathrm{F}-\mathrm{TiO}_{2}$ photocatalyst is lower than that of the pure $\mathrm{F}_{-}-\mathrm{TiO}_{2}$. It indicates that doping $\mathrm{CuO}$ is helpful to inhibit the recombination of electrons and holes and improve the photocatalytic activity. At the same time, it was reported that ptype semiconductor is a collector of photoexcited holes [35]. Therefore, there are enrichment electrons in the interface to react with $\mathrm{Cr}_{2} \mathrm{O}_{7}{ }^{2-}$ adsorbed on the photocatalyst surface, so the $\mathrm{p}-\mathrm{n}$ heterojunction photocatalyst $\mathrm{CuO} / \mathrm{F}-\mathrm{TiO}_{2}$ has higher photocatalytic reduction activity, but lower photocatalytic oxidation activity.

3.2.3. Effect of Ball Milling Time on the Photocatalytic Activity. The effect of ball milling time on the photocatalytic activity of $\mathrm{CuO}(1.0 \mathrm{wt} . \%) / \mathrm{F}-\mathrm{TiO}_{2}$ photocatalyst is shown in Figure 8 . It can be seen that the ball milling time influences the photocatalytic activity strongly. Without ball milling, the photoreduction efficiency is $39.2 \%$, and the photooxidation efficiency is $51.3 \%$. The photoreduction efficiency of $\mathrm{Cr}_{2} \mathrm{O}_{7}{ }^{2-}$ increases gradually with the increase in ball milling time up to $6 \mathrm{~h}$. When the ball milling time is $1,3,6,12$, and $24 \mathrm{~h}$, the photoreduction efficiency is $45.5,61.2,76.8,74.2$, and $70.1 \%$, respectively. For the photocatalytic oxidation of $\mathrm{RhB}$, the photooxidation efficiency decreases rapidly with the increase in the ball milling time. When the ball milling time is $1 \mathrm{~h}$, the photooxidation efficiency is the lowest, and it is $32.7 \%$. However, when the ball milling time is longer than $1 \mathrm{~h}$, the photooxidation efficiency increases gradually with the increase in ball milling time up to $6 \mathrm{~h}$. When the ball milling time is $6 \mathrm{~h}$, the photooxidation efficiency of RhB is $40.6 \%$. When the ball milling time is longer than $6 \mathrm{~h}$, the photooxidation efficiency decreases gradually. The reason is that, without ball milling, $\mathrm{F}_{-} \mathrm{TiO}_{2}$ and $\mathrm{p}-\mathrm{CuO}$ only play their own photocatalytic role, and the $\mathrm{p}-\mathrm{n}$ junction photocatalysts are not formed. However, after ball milling, $\mathrm{TiO}_{2}$ and $\mathrm{p}-\mathrm{CuO}$ can form $\mathrm{p}-\mathrm{n}$ junction photocatalyst, which results in the increase of the photoreduction activity and the decrease of the photooxidation activity rapidly. Another reason is that, with the increase in the ball milling time, the specific surface area of the photocatalyst increases. Correspondingly, the number of active sites per unit weight of photocatalyst also increases [21]. But when the ball milling time is longer than the optimum time, it is proposed that, with the increase in the ball milling time, the fresh surface formed by high-energy ball milling possesses high surface energy and prefers to agglomerate [36, 37], resulting in the decrease of the photocatalytic activity. The assumption is proved by the results of SEM.

3.2.4. Hydroxyl Radical Analysis. The formation of hydroxyl radicals $(\cdot \mathrm{OH})$ on the surface of $\mathrm{CuO}(1.0 \mathrm{wt} . \%) / \mathrm{F}-\mathrm{TiO}_{2}$ photocatalyst is detected by a photoluminescence (PL) technique with terephthalic acid as a probe molecule. The method is rapid, sensitive, and specific, needing only simple standard PL instrumentation. Terephthalic acid readily reacts with ${ }^{\bullet} \mathrm{OH}$ to produce a highly fluorescent product, 2-hydroxyterephthalic acid, whose PL peak intensity is in proportion to the amount of $\mathrm{OH}$ radicals produced in water. Experimental procedures were reported in earlier reports [27]. After UV irradiation for $10 \mathrm{~min}$, the reaction solution was filtrated to measure the PL intensity at $425 \mathrm{~nm}$ excited by $315 \mathrm{~nm}$ light of 2-hydroxyterephthalic acid.

Figure 9 shows the changes of PL spectra of different samples from $5 \times 10^{-4} \mathrm{~mol} / \mathrm{L}$ terephthalic acid solution in $2 \times 10^{-3} \mathrm{~mol} / \mathrm{L} \mathrm{NaOH}$. From Figure 9, it can be seen that, when the ball milling time is $6 \mathrm{~h}$, the PL peak intensity of the sample is the highest. It means that the formation rate of 


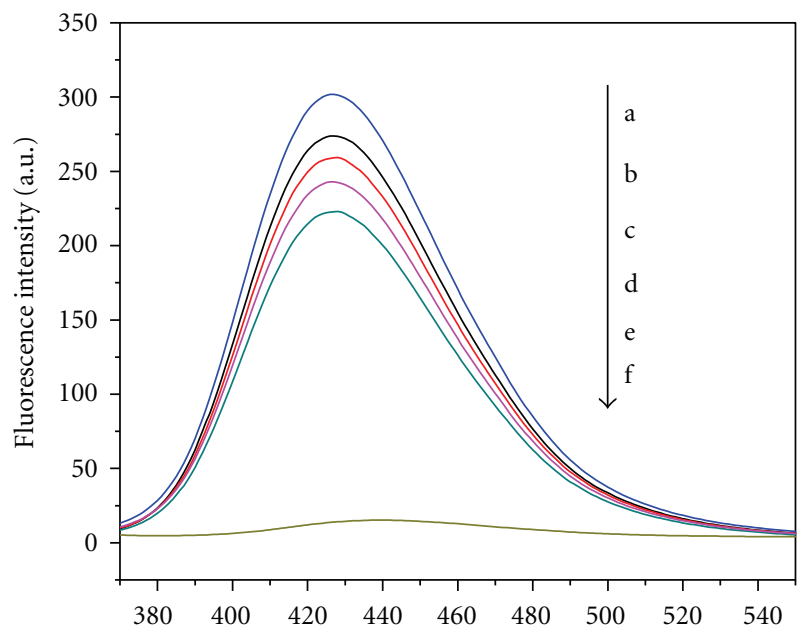

FIGURE 9: Effect of ball milling time on the changes of PL spectra. (a) $6 \mathrm{~h}$, (b) $3 \mathrm{~h}$, (c) $12 \mathrm{~h}$, (d) $24 \mathrm{~h}$, (e) $1 \mathrm{~h}$, (f) pure terephthalic acid.

$\mathrm{OH}$ radicals on its surface is much larger than that of other samples. The PL peak intensities of the samples decrease are as follows: ball milling time $6 \mathrm{~h}>3 \mathrm{~h}>12 \mathrm{~h}>24 \mathrm{~h}>1 \mathrm{~h}$. The result of PL peak intensity is consistent with that of the photooxidation activity.

\section{Conclusions}

The $\mathrm{CuO} / \mathrm{F}-\mathrm{TiO}_{2}$ photocatalyst was prepared by ball milling method. The photooxidation activity of $\mathrm{F}-\mathrm{TiO}_{2}$ increases greatly with the increase in the amount of $\mathrm{NH}_{4} \mathrm{~F}$ up to $1.0 \mathrm{~g}$. The photoreduction activity of $\mathrm{CuO} / \mathrm{F}-\mathrm{TiO}_{2}$ increases remarkably with the increase in the amount of doped $\mathrm{p}$ $\mathrm{CuO}$ up to $1.0 \mathrm{wt} . \%$. The ball milling time has a significant influence on the photocatalytic activity of the photocatalyst. The optimum ball milling time is $6 \mathrm{~h}$. Compared with pure $\mathrm{TiO}_{2}$, the photoabsorption wavelength range of the $\mathrm{F}-\mathrm{TiO}_{2}$ and $\mathrm{CuO} / \mathrm{F}-\mathrm{TiO}_{2}$ photocatalysts red shifts and improves the utilization of the total spectrum. As the formation of the p$\mathrm{n}$ heterojunction and $\mathrm{p}$-type $\mathrm{CuO}$ species acts as holes traps and collector, the photogenerated electron-hole pairs of the $\mathrm{CuO} / \mathrm{F}-\mathrm{TiO}_{2}$ photocatalyst are separated by the inner electric field and the photocatalytic reduction activity is enhanced greatly.

\section{Acknowledgments}

This study was supported by the Natural Science Foundation of China (nos. 20973071, 51172086, and 21103060) and the Key Project of Science and Technology Research of Ministry of Education of China (208062).

\section{References}

[1] A. Fujishima and K. Honda, "Electrochemical photolysis of water at a semiconductor electrode," Nature, vol. 238, no. 5358, pp. 37-38, 1972.

[2] T. Yan, J. Long, X. Shi, D. Wang, Z. Li, and X. Wang, "Efficient photocatalytic degradation of volatile organic compounds by porous indium hydroxide nanocrystals," Environmental Science and Technology, vol. 44, no. 4, pp. 1380-1385, 2010.

[3] X. Xin, M. Scheiner, M. Ye, and Z. Lin, "Surface-treated $\mathrm{TiO}_{2}$ nanoparticles for dye-sensitized solar cells with remarkably enhanced performance," Langmuir, vol. 27, no. 23, pp. 1459414598, 2011.

[4] X. Xu, X. Li, P. Lin et al., "A general templated method to homogeneous and composition-tunable hybrid $\mathrm{TiO}_{2}$ nanocomposite fibers," Chemical Communications, vol. 47, no. 9, pp. 2538-2540, 2011.

[5] Z. J. Zhou, J. Q. Fan, X. Wang, W. H. Zhou, Z. L. Du, and S. X. $\mathrm{Wu}$, "Effect of highly ordered single-crystalline $\mathrm{TiO}_{2}$ nanowire length on the photovoltaic performance of dye-sensitized solar cells," ACS Applied Materials \& Interfaces, vol. 3, pp. 43494353, 2011.

[6] K. Lv, J. Yu, J. Fan, and M. Jaroniec, "Rugby-like anatase titania hollow nanoparticles with enhanced photocatalytic activity," CrystEngCommunity, vol. 13, no. 23, pp. 7044-7048, 2011.

[7] D. Yang, C. Chen, Z. Zheng et al., "Grafting silica species on anatase surface for visible light photocatalytic activity," Energy and Environmental Science, vol. 4, no. 6, pp. 2279-2287, 2011.

[8] Y. Wang, D. Zhao, H. Ji et al., "Sonochemical hydrogen production efficiently catalyzed by $\mathrm{Au} / \mathrm{TiO}_{2}$," Journal of Physical Chemistry C, vol. 114, no. 41, pp. 17728-17733, 2010.

[9] R. Shi, J. Lin, Y. Wang, J. Xu, and Y. Zhu, "Visible-light photocatalytic degradation of $\mathrm{BiTaO}_{4}$ photocatalyst and mechanism of photocorrosion suppression," Journal of Physical Chemistry C, vol. 114, no. 14, pp. 6472-6477, 2010.

[10] R. J. Wang, G. H. Jiang, Y. W. Ding et al., "Photocatalytic activity of heterostructures based on $\mathrm{TiO}_{2}$ and halloysite nanotubes," ACS Applied Materials \& Interfaces, vol. 3, pp. 4154-4158, 2011.

[11] D. Y. Wu and M. Long, "Realizing visible-light-induced selfcleaning property of cotton through coating $\mathrm{N}-\mathrm{TiO}_{2}$ film and loading AgI particles," ACS Applied Materials \& Interfaces, vol. 3, pp. 4770-4774, 2011.

[12] M. Liu, X. Qiu, M. Miyauchi, and K. Hashimoto, " $\mathrm{Cu}(\mathrm{II})$ oxide amorphous nanoclusters grafted $\mathrm{Ti}^{3+}$ self-doped $\mathrm{TiO}_{2}$ : an efficient visible light photocatalyst," Chemistry of Materials, vol. 23, no. 23, pp. 5282-5286, 2011.

[13] N. Zhang, S. Liu, X. Fu, and Y.-J. Xu, "Synthesis of $\mathrm{M@TiO}_{2}$ $(\mathrm{M}=\mathrm{Au}, \mathrm{Pd}, \mathrm{Pt})$ core-shell nanocomposites with tunable photoreactivity," Journal of Physical Chemistry C, vol. 115, no. 18, pp. 9136-9145, 2011.

[14] T. A. Kandiel, A. A. Ismail, and D. W. Bahnemann, "Mesoporous $\mathrm{TiO}_{2}$ nanostructures: a route to minimize Pt loading on titania photocatalysts for hydrogen production," Physical Chemistry Chemical Physics, vol. 13, no. 45, pp. 20155-20161, 2011.

[15] P. Sangpour, F. Hashemi, and A. Z. Moshfegh, "Photoenhanced degradation of methylene blue on cosputtered $\mathrm{M}: \mathrm{TiO}_{2}(\mathrm{M}=\mathrm{Au}, \mathrm{Ag}, \mathrm{Cu})$ nanocomposite systems: a comparative study," Journal of Physical Chemistry C, vol. 114, no. 33, pp. 13955-13961, 2010.

[16] K. Yang, Y. Dai, and B. Huang, "Density functional study of boron-doped anatase $\mathrm{TiO}_{2}$," Journal of Physical Chemistry C, vol. 114, no. 46, pp. 19830-19834, 2010.

[17] P. Xu, J. Lu, T. Xu, S. Gao, B. Huang, and Y. Dai, "I2-hydrosolseeded growth of $\left(\mathrm{I}_{2}\right)_{\mathrm{n}}$-C-codoped meso/nanoporous $\mathrm{TiO}_{2}$ for visible light-driven photocatalysis," Journal of Physical Chemistry C, vol. 114, no. 20, pp. 9510-9517, 2010.

[18] W. Guo, Y. Shen, L. Wu, Y. Gao, and T. Ma, "Effect of N dopant amount on the performance of dye-sensitized solar cells based on $\mathrm{N}$-Doped $\mathrm{TiO}_{2}$ electrodes," Journal of Physical Chemistry C, vol. 115, no. 43, pp. 21494-21499, 2011. 
[19] J. Lin, J. Lin, and Y. Zhu, "Controlled synthesis of the $\mathrm{ZnWO}_{4}$ nanostructure and effects on the photocatalytic performance," Inorganic Chemistry, vol. 46, no. 20, pp. 8372-8378, 2007.

[20] A. T. Kuvarega, R. W. M. Krause, and B. B. Mamba, "Nitrogen/palladium-codoped $\mathrm{TiO}_{2}$ for efficient visible light photocatalytic dye degradation," Journal of Physical Chemistry C, vol. 115, no. 45, pp. 22110-22120, 2011.

[21] S. Chen, W. Zhao, W. Liu, and S. Zhang, "Preparation, characterization and activity evaluation of $\mathrm{p}-\mathrm{n}$ junction photocatalyst p-ZnO/n- $\mathrm{TiO}_{2}$," Applied Surface Science, vol. 255, no. 5, pp. 2478-2484, 2008.

[22] Z.-R. Tang, F. Li, Y. Zhang, X. Fu, and Y.-J. Xu, "Composites of titanate nanotube and carbon nanotube as photocatalyst with high mineralization ratio for gas-phase degradation of volatile aromatic pollutant," Journal of Physical Chemistry C, vol. 115, no. 16, pp. 7880-7886, 2011.

[23] V. Štengl, D. Popelková, and P. Vláčil, “ $\mathrm{TiO}_{2}$-graphene nanocomposite as high performace photocatalysts," Journal of Physical Chemistry C, vol. 115, no. 51, pp. 25209-25218, 2011.

[24] J. Zhang, J. Yu, Y. Zhang, Q. Li, and J. R. Gong, "Visible light photocatalytic $\mathrm{H}_{2}$-production activity of $\mathrm{CuS} / \mathrm{ZnS}$ porous nanosheets based on photoinduced interfacial charge transfer," Nano Letters, vol. 11, no. 11, pp. 4774-4779, 2011.

[25] H. Park and W. Choi, "Effects of $\mathrm{TiO}_{2}$ surface fluorination on photocatalytic reactions and photoelectrochemical behaviors," Journal of Physical Chemistry B, vol. 108, no. 13, pp. 40864093, 2004.

[26] W. Choi, "Pure and modified $\mathrm{TiO}_{2}$ photocatalysts and their environmental applications," Catalysis Surveys from Asia, vol. 10, no. 1, pp. 16-28, 2006.

[27] J. Yu, W. Wang, B. Cheng, and B. L. Su, "Enhancement of photocatalytic activity of Mesporous $\mathrm{TiO}_{2}$ powders by hydrothermal surface fluorination treatment," Journal of Physical Chemistry C, vol. 113, no. 16, pp. 6743-6750, 2009.

[28] S. F. Chen, S. J. Zhang, W. Liu, and W. Zhao, "Preparation and activity evaluation of $\mathrm{p}-\mathrm{n}$ junction photocatalyst $\mathrm{NiO} / \mathrm{TiO}_{2}$," Journal of Hazardous Materials, vol. 155, no. 1-2, pp. 320-326, 2008.

[29] H. Yu, J. Yu, S. Liu, and S. Mann, "Template-free hydrothermal synthesis of $\mathrm{CuO} / \mathrm{Cu}_{2} \mathrm{O}$ composite hollow microspheres," Chemistry of Materials, vol. 19, no. 17, pp. 4327-4334, 2007.

[30] S. F. Chen, L. Chen, S. Gao, and G. Y. Cao, "The preparation of nitrogen-doped photocatalyst $\mathrm{TiO}_{2}-\mathrm{XN}$ x by ball milling," Chemical Physics Letters, vol. 413, no. 4-6, pp. 404-409, 2005.

[31] T. Cai, M. Yue, X. Wang, Q. Deng, Z. Peng, and W. Zhou, "Preparation, characterization, and photocatalytic performance of $\mathrm{NdPW}_{12} \mathrm{O}_{40} / \mathrm{TiO}_{2}$ composite catalyst," Chinese Journal of Catalysis, vol. 28, no. 1, pp. 10-16, 2007.

[32] J. W. Tang, Z. G. Zou, and J. H. Ye, "Photophysical and photocatalytic properties of $\mathrm{AgInW}_{2} \mathrm{O}_{8}$," The Journal of Physical Chemistry B, vol. 107, pp. 14265-14269, 2003.

[33] S. Kang, K. Shin, K. Prabakar, and C. Lee, "Optical and electrical properties of $\mathrm{ZnO}$ doped with nitrogen," Physica Status Solidi B, vol. 241, no. 12, pp. 2830-2834, 2004.

[34] S. F. Chen, X. L. Yu, H. Y. Zhang, and W. Liu, "Preparation and photocatalytic activity evaluation of composite $\mathrm{Fe}-\mathrm{TiO}_{2} / \mathrm{TiO}_{2}$ photocatalyst," Journal of the Electrochemical Society, vol. 157, no. 5, pp. K96-K102, 2010.

[35] A. Lohner, M. Woerner, T. Elsaesser, and W. Kaiser, "Picosecond capture of photoexcited holes by shallow acceptors in ptype GaAs," Physical Review Letters, vol. 68, no. 26, pp. 3920 3923, 1992.

[36] S. F. Chen, L. Chen, G. Shen, and C. Gengyu, "The preparation of coupled $\mathrm{WO}_{3} / \mathrm{TiO}_{2}$ photocatalyst by ball milling," Powder Technology, vol. 160, no. 3, pp. 198-202, 2005.
[37] J. Wang, S. Yin, M. Komatsu, Q. Zhang, F. Saito, and T. Sato, "Preparation and characterization of nitrogen doped $\mathrm{SrTiO}_{3}$ photocatalyst," Journal of Photochemistry and Photobiology A, vol. 165, no. 1-3, pp. 149-156, 2004. 


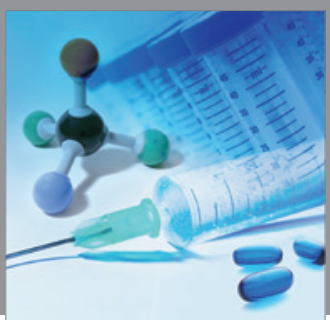

International Journal of

Medicinal Chemistry

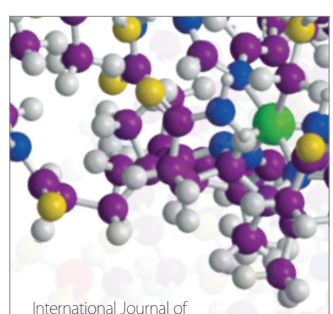

Carbohydrate Chemistry

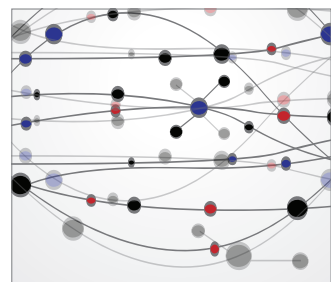

The Scientific World Journal
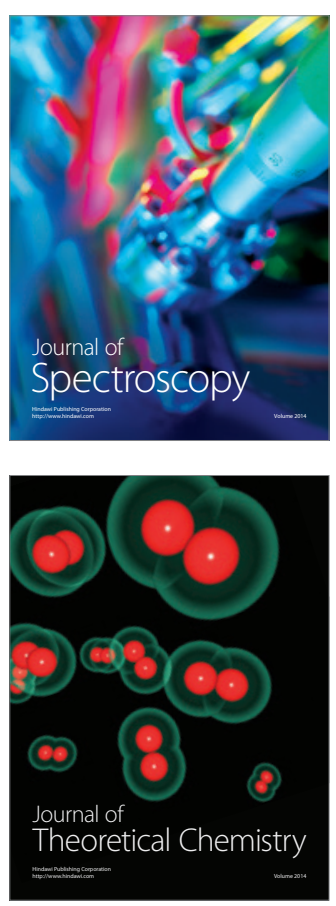
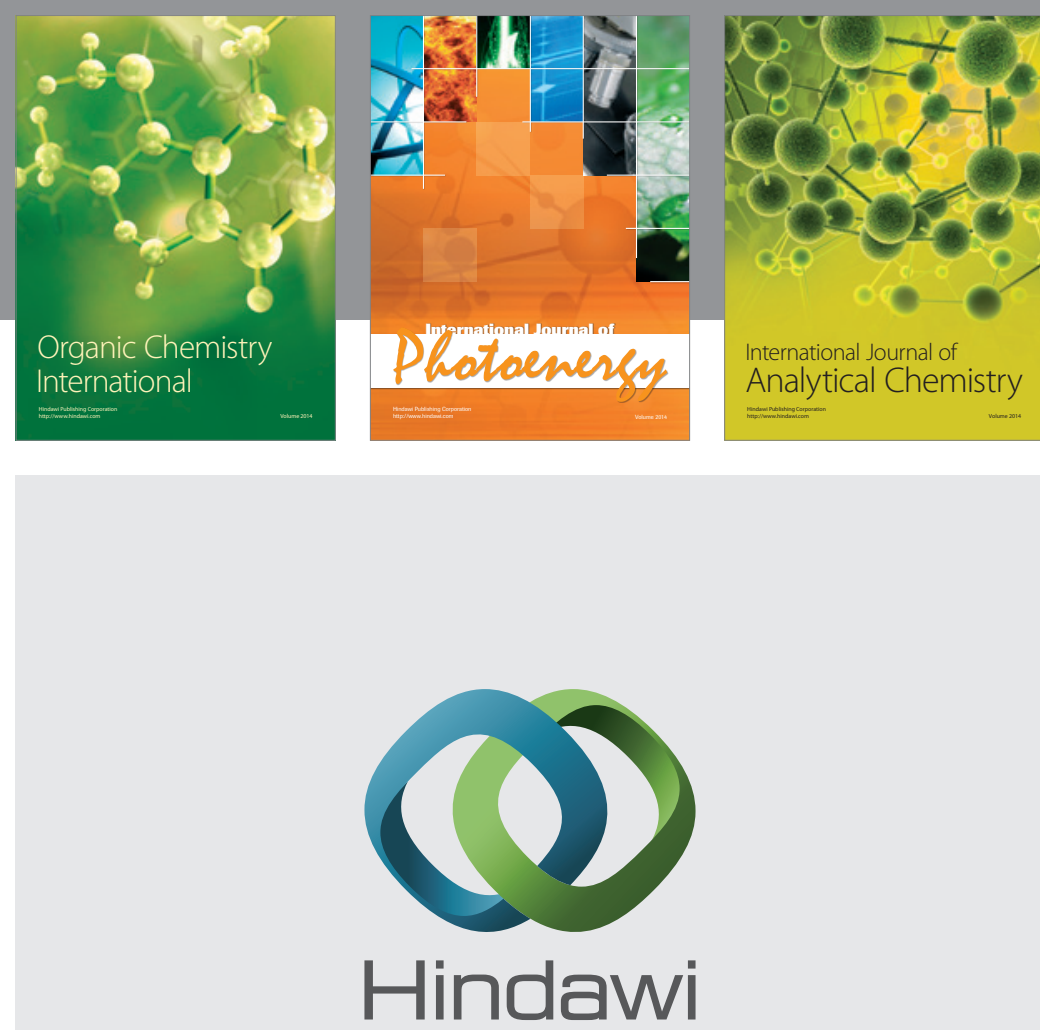

Submit your manuscripts at

http://www.hindawi.com
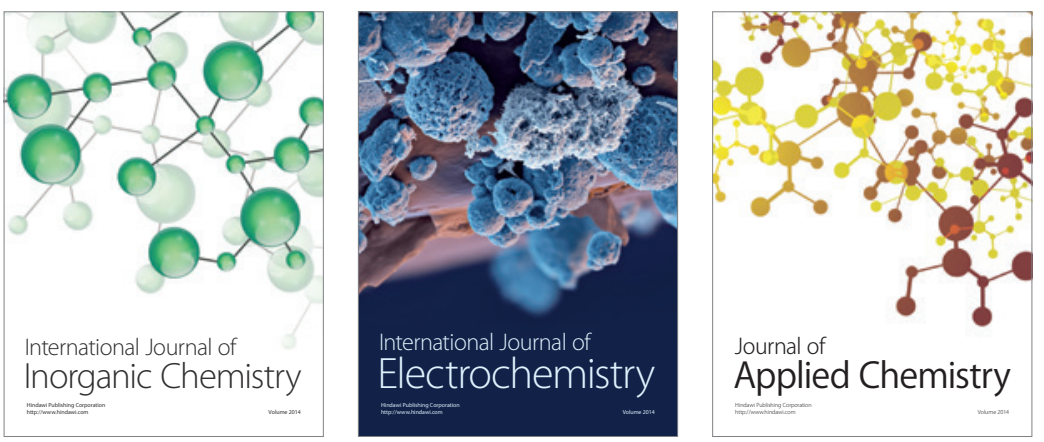

Journal of

Applied Chemistry
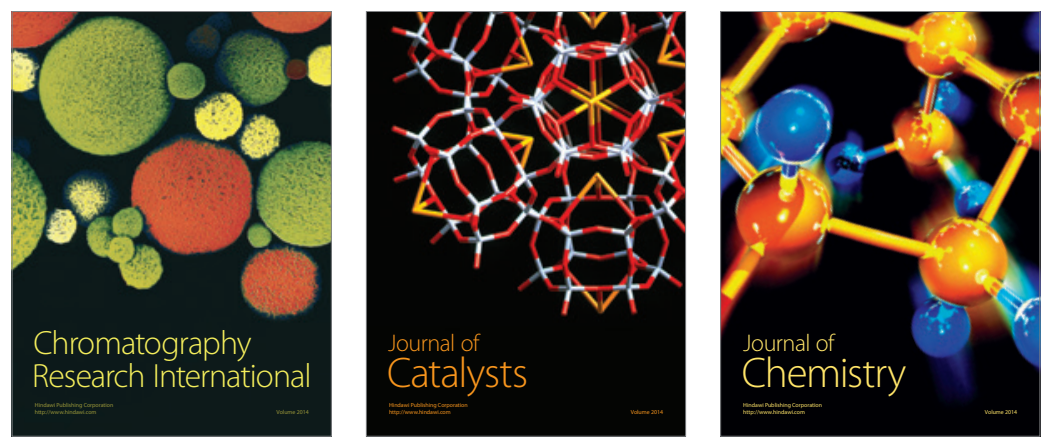
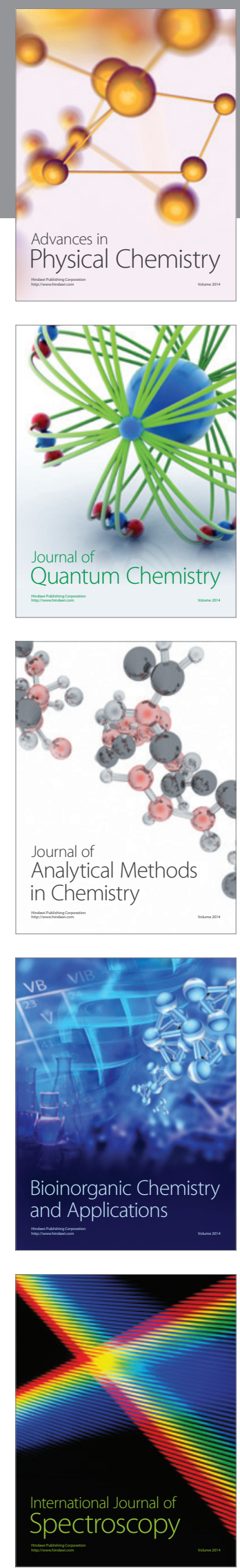